\title{
AUV development trends and their implications for risk management strategies
}

Autonomous underwater vehicles (AUV) have been under substantial development since the 1980s. The first AUV, the self-propelled underwater research vehicle (SPURV), was built in 1957, at the University of Washington's Applied Physics Laboratory (Widditsch, 1973). Other early AUVs were built in the 1980s, such as the L'Epaulard and the ARCS built by the Institut Français de Recherche pour l'Exploitation de la Mer (IFREMER, 2017) and International Submarine Engineering (ISE, 2017) respectively.

Here I argue that the risk management strategy adopted in the early days is still in use for most AUV operations but is unsuitable for informing decision making for modern AUV operations.

A risk management strategy, or strategic framework, is a multifaceted set of design considerations that underpin the implementation of the risk management process (Ward, 2005). It is partly concerned with the philosophical and cultural context for risk management practice, and seeks to influence and improve how people engage with problems or situations. For example, one concept commonly identified as a vital enabler for early and effective responses to possible risk is ' $m i n d-$ fulness' (Weick and Sutcliffe, 2001) which is perhaps best known as a state of mind advocated by the teachings of Buddhism where it promotes meditation in order to reflect on experiences.

Mindfulness, when considered as a risk management strategy, comprises psychological techniques aimed at ensuring constant vigilance against the unexpected. It consists of a combination of on-going scrutiny of existing expectations, and continuous refinement and differentiation of expectations based on new experiences. Arguably, mindfulness was the risk management strategy adopted by the early AUV owners. One of the dangers of following a mindfulness risk management strategy is that it consumes a great deal of resources in attending to what often turn out to be false positive errors.

Many AUV pioneers had only one vehicle to operate and this understandably influenced a conservative operational mindset. There was relatively little scope for experimental learning through flexibility (Hamblin, 2002). This is a risk management strategy that advocates the definition of alternative states of success and ongoing experimentation to learn and re-evaluate what success can mean.

The exception to conventional AUV deployments are the long endurance missions carried out underneath ice covered areas, such as the missions of Autosub 3 under the Pine Island Glacier in 2009 and 2013 and the missions of ISE Arctic Explorer as part of the Cornerstone Project (Brito et al., 2010; 2012). Here a resilience risk management strategy was adopted, which favoured mitigation rather than a constant review of objectives. For these missions, mitigation was applied in terms of improving the robustness of design vulnerabilities and introducing a monitoring distance. The resilience philosophy seeks to manage the entire cycle of unexpected events from first detection

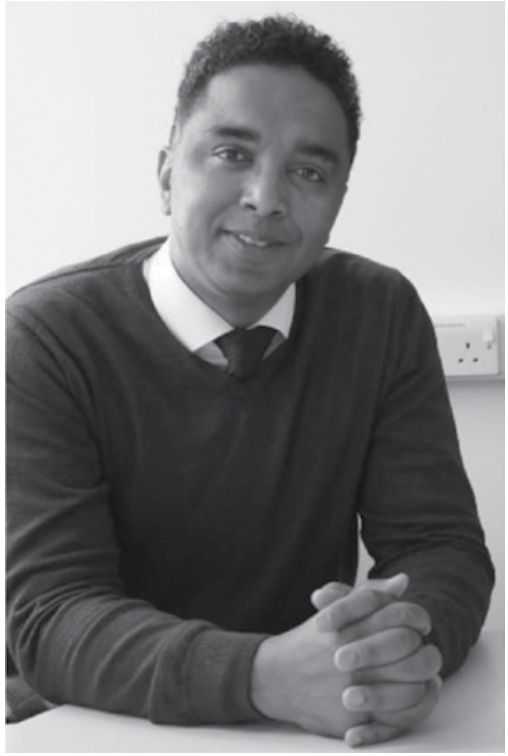

Dr Mario P Brito

Dr Mario $P$ Brito is a Lecturer in Risk Analysis and Risk Management at the University of Southampton. He has a degree in Aeronautical Engineering from the University of Beira Interior, Portugal and a $\mathrm{PhD}$ in Software Reliability Assurance and Management, awarded by the University of Bristol. Dr Brito has conducted several risk and reliability analyses of autonomous underwater vehicles and delivers courses to the industry on how to use these methods. He has also chaired several accident investigations of underwater technology. Dr Brito is the Deputy chair of the SUT/ECOR panel on Underwater Robotics, he is Co-Chair of the European Safety and Reliability Association Committee on Marine and Offshore Technology and is a member of the Institute of Engineering and Technology (IET).

through crisis management and eventual return to normalcy. Such mitigations were planned on a combined ex ante and ex post basis that is, through the planning of both precautionary and remedial risk controls.

In the last five years, technological developments and substantial investment from both government 
and industry have led to an increased confidence that AUV technology can be used successfully for more complex applications. These trends, some of them highlighted in the early days of AUV development, force us to question the suitability of risk management strategies adopted thus far. Some trends by their own nature imply the use of a certain risk management strategy, whereas for other trends there is currently a lack of a risk management strategy. There are three key new trends in AUV development that could benefit from a new risk management strategy:

1. Higher autonomy. Several large research projects have sought to increase the autonomy of AUVs. The aim is to augment AUV capability by enabling platforms to conduct intervention tasks such as valve turning (PANDORA, 2017), to search for explosive mines and to identify and track physical, chemical and biological features (Monterey Bay Aquarium Research Institute, 2017; Natural Environment Research Council, 2017).

2. Multiple vehicle operations. Self-configuration AUVs have been proposed as solutions for optimal sampling of ocean fronts, large eddies and other mesoscale ocean processes (L'Hévéder et al., 2013). Virtual moorings also provide a solution for expensive mooring deployments (Alvarez and Mourre, 2011; Hodges and Fratantoni, 2009; Smeed et al., 2013).

3. Deeper and long endurance AUVs. Both commerce and science have a stake in increasing the depth and range of platforms. Ocean explorations and sea mining are expected to reach deeper regions of the ocean than ever and there is now a strong emphasis on developing AUVs capable of operating at depths of $6000 \mathrm{~m}$ (McPhail, 2008). Mindfulness is of course important for any new technology development. However, for a wider group of AUV users, developers must adopt a fuller range of risk management strategies that must be hybridised and sometimes traded off against one another. A criticism raised about the first trend listed above is the uncertainty associated with the platform behaviour at a given point of the mission. To address this problem a combination of other general strategies such as anticipation and resilience is required. Both imply that the mission objective must be met. In contrast to resilience, anticipation does not favour mitigation. The mind set for anticipation is one that favours precise identification of possible problems so that specific remedies can be designed or recalled. The use of this risk management strategy alone can be dangerous, because it presumes a level of understanding that is impossible to achieve when dealing with unknowable and unpredictable environments. A resilience strategy can also be applied to higher level autonomous systems by the implementation of mitigation functions in the design or operation phases.

Multiple vehicle operations favour the use of flexibility or slack. Here we have both the ability to reach other acceptable states and excess capability (Nãslund, 1964). In technical terms going deeper and for longer missions only implies more robust pressure housings and connections, more powerful energy supplies and more energy efficient systems and design. Of course, developers must be mindful of the technological limitations. However, resilience is also crucial particularly in mission planning, where the mitigation actions and recovery procedures must be defined for different stages of the deployment.

These arguments do not consider any overlap between trends. If there is overlap, then the risk strategies suggested for the trends involved must be applied. For example, if for one application, the developer is considering a long endurance mission with high autonomy then anticipation, mindfulness and resilience strategies should be applied.

Once there is agreement on a risk management strategy, the next stage is to consider how to implement the strategy in a given organisation or project. Here several risk management frameworks can be adopted. The IRM framework provides guidelines for implementing risk management processes (IRM, 2002). This and other risk management frameworks have been developed by risk managers, engineers, accountants and financial analysts. These can be tailored to any technology or organisation.

In my view, a fundamental feature in persuading others to adopt AUVs is the level of transparency regarding risks as well as opportunities. Naturally, being very enthusiastic about technology makes developers better at articulating the opportunities rather than the risks. Identifying the risk management strategy before building the risk management process enables developers to objectively communicate the advantage of autonomous underwater vehicles.

\section{References}

Alvarez AA and Mourre BB. (2012). Optimum Sampling Designs for a Glider-Mooring Observing Network. Journal of Atmospheric and Oceanic Technology 29: 601-612.

Brito MP, Griffiths G and Challenor P. (2010). Risk Analysis for Autonomous 
Underwater Vehicle Operations in Extreme Environments. Risk Analysis 30: 1771-1788.

Brito M, Griffiths G, Ferguson J, Hopkin, D, Mills R, Pederson R and MacNeil E. (2012). A Behavioral Probabilistic Risk Assessment Framework for Managing Autonomous Underwater Vehicle Deployments. Journal of Atmospheric and Oceanic Technology 29: 1689-1703.

Hamblin DG. (2002). Rethinking the management of flexibility-a study in the aerospace defence industry. Journal of the Operational Research Society 53: 272-282.

Hodges BA and Fratantoni DM (2009). A thin layer of phytoplankton observed in the Philippine Sea with a synthetic moored array of autonomous gliders. Journal of Geophysical Research 114: C10020.

Institut Français de Recherche pour l'Exploitation de la Mer (IFREMER). (2017).

Institute of Risk Management (IRM). (2002). A risk management standard. London: Institute of Risk Management. Available at: www.theirm.org/ media/886059/ARMS_2002_IRM. pdf $<$ last accessed on 25/05/2017 $>$.
L'Epaulard. Available at: http://wwz. ifremer.fr/grands_fonds/Les-moyens/Les-engins/Les-robots/RobotsIfremer/L-Epaulard <last accessed 3 May 2017>.

International Submarine Engineering (ISE). (2017). ARCS. Available at: www.ise.bc.ca/arcs.html <lastaccessed on $03 / 05 / 2017>$.

L'Hévéder B, Mortier L and Testor P. (2013). A glider network design study for a synoptic view of the oceanic mesoscale variability. Journal of Atmospheric and Oceanic Technology 30: 1472-1493.

McPhail S. (2008). Autosub6000: a deep diving long range AUV. In: Proceedings of the 2nd International Conference on Underwater System Technology Theory and Applications (USYS), 4-5 November 2008, Bali, Indonesia. 6pp.

Monterey Bay Aquarium Research Institute (MBARI). (2017). Tracking drifting algal blooms and the nutrients that keep them going. Available at: www. mbari.org/tracking-drifting-algalblooms-and-the-nutrients-that-keepthem-going <last accessed 3 May 2017>.

Nãslund B. (1964). Organizational Slack. Scandinavian Journal of Economics 66: 26-31.
National Environment Research Council (NERC). (2017). NERC Autonomy Joint Strategic Research. Available at: www.nerc.ac.uk/research/ funded/programmes/autonomous/ news/miaos-ao/dstl/ <last accessed 25/5/2017>.

PANDORA (2017). Persistent Autonomous Robots (PANDORA). Available at: http://persistentautonomy. com/ <last accessed 3 May 2017>.

Smeed D, McCarthy G and White D. (2013). Underwater gliders as virtual moorings; lessons from the RAPID program. In Proceedings of the European Geosciences Union General Assembly 2013, 7-12 April 2013, Vienna, Austria.

Ward S. (2005). Risk Management Organization and Context. London: Witherlby \& Co. 222pp.

Weick KE and Sutcliffe KM. (2001). Managing the Unexpected: resilient performance in an age of uncertainty. San Francisco: John Wiley \& Sons, 194pp.

Widditsch HR. (1973). SPURV- The First Decade, APL-UW 7215. University of Washington. Available at: http://dtic. mil/dtic/tr/fulltext/u2/a050816.pdf $<$ last accessed 25/5/2017>. 